

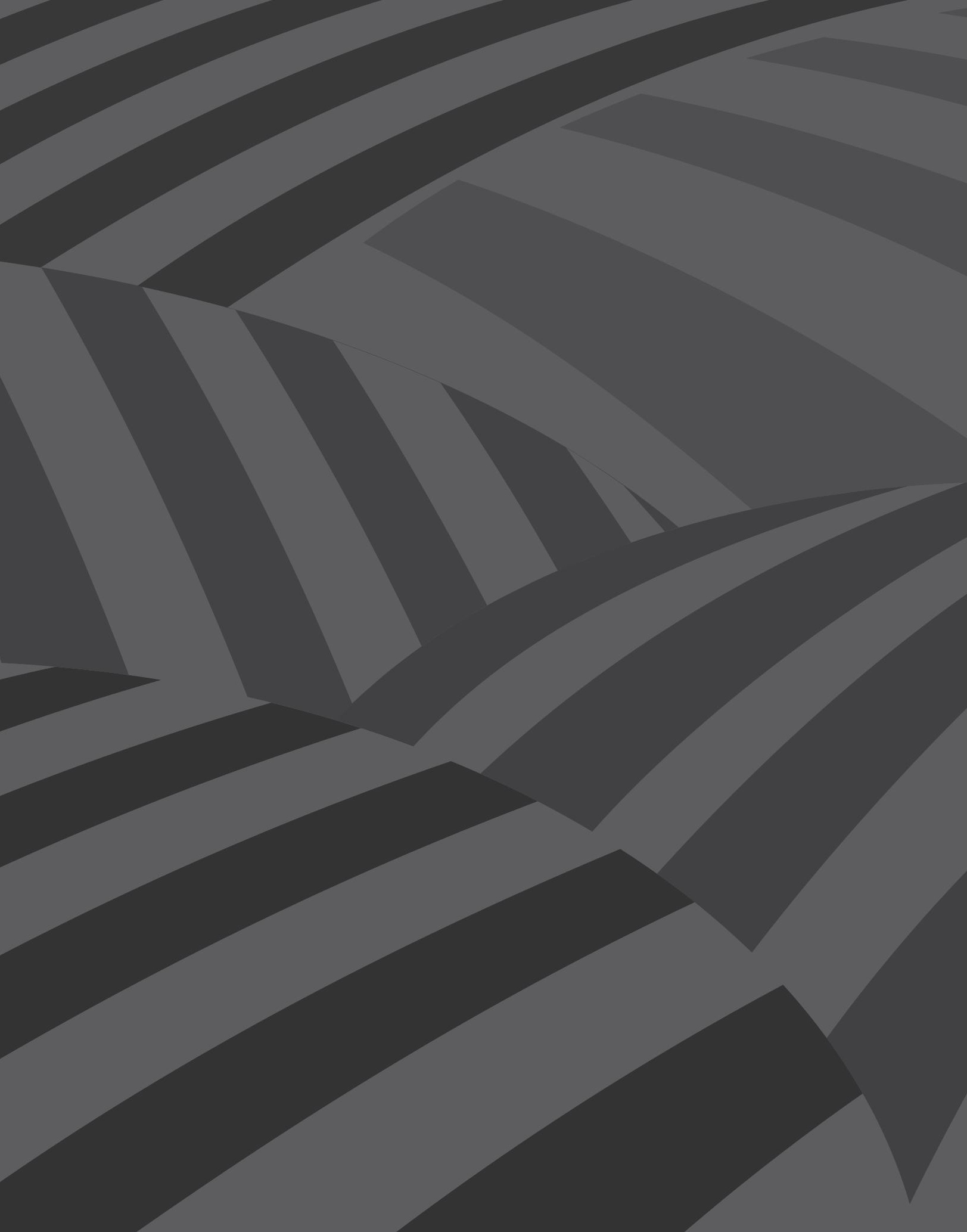




\title{
Afrodescendientes, de la crisis estructural a la pandemia de COVID-19
}

\author{
Por Carlos Agudelo*
}

Resumen: Este trabajo quiere hacer una contribución a los estudios sobre las repercusiones de la pandemia de la COVID-19 en los afrodescendientes. Contiene una revisión no exhaustiva de documentación de dos fuentes fundamentales: organismos multilaterales y organizaciones afrodescendientes. Esta problemática está inserta en una crisis estructural anterior a la pandemia. Finalmente, se llama la atención sobre una especie de consenso en los diagnósticos acerca de los impactos negativos de la pandemia y de sus raíces en problemas estructurales de desigualdad, racismo y exclusión. La paradoja es la brecha entre la justeza de estos discursos y la implementación práctica de soluciones. Alternativas esbozadas por movimientos afrodescendientes se ubican en el terreno de la lucha política y de la confluencia con otros sectores que plantean un necesario cambio de modelo de sociedad.

Palabras clave: afrodescendientes, pandemia, COVID-19, racismo, desigualdades, crisis.

\section{Afrodescendants, from Structural Crisis to the COVID-19 Pandemic}

Abstract: This paper aims to make a contribution to studies on the impact of the COVID-19 pandemic on people of African descent. It contains a non-exhaustive review of documentation from two fundamental sources: multilateral agencies and Afro-descendant organizations. This problematic is embedded in a structural crisis prior to the pandemic. Finally, attention is drawn to a kind of consensus in the diagnoses about the negative impacts of the pandemic and its roots in structural problems of inequality, racism and exclusion. The paradox is the gap between the correctness of these discourses and the practical implementation of solutions. Alternatives outlined by Afro-descendant movements are located in the field of political struggle and confluence with other sectors that propose a necessary change in the model of society.

* Doctor en sociología. Investigador asociado de la Unidad Mixta de Investigación URMIS - Sociedades y Migraciones de Francia. Especialista en multiculturalismo, ciudadanía, política e identidades de poblaciones afrodescendientes. Correo electrónico: agudelo04@yahoo.fr 
Key words: afrodescendants, pandemic, COVID-19, racism, inequalities, crisis.

Cómo citar este artículo: Agudelo, Carlos. Afrodescendientes, de la crisis estructural a la pandemia de COVID-19. Revista Controversia, 216, 89-129.

Fecha de recepción: 19 de octubre de 2020.

Fecha de aprobación: 9 de diciembre de 2020.

0 in duda uno de los elementos que se decantaron desde los primeros análisis sobre el surgimiento de la pandemia de la COVID-19, más allá de su evidente impacto sanitario, fue el de los efectos diferenciados del virus en función de las desigualdades sociales. La lectura inicial sobre un virus global y “democrático” que ataca por igual a ricos y pobres se desvaneció rápidamente. Pronto se evidenciaron los desequilibrios que hacían de los sectores más fragilizados de nuestras sociedades, las principales víctimas de la pandemia.

Entre los grupos considerados con mayor vulnerabilidad frente a los embates de la COVID-19, tanto sanitarios como sociales en general, están las poblaciones afrodescendientes. La pandemia llega en un momento que ya es crítico en materia de desigualdades estructurales irresueltas que afectan a los sectores más pobres de la sociedad, así como a los grupos humanos víctimas de múltiples formas de discriminación y de injusticia.

Son variados y disímiles los sectores desde los que se expresan análisis, opiniones y datos sobre la pandemia y sus efectos en los afrodescendientes. Pero más allá de los matices que dichos sectores pueden tener en sus interpretaciones sobre la coyuntura actual y sus antecedentes, todos coinciden en señalar las desigualdades como un elemento transversal que afecta a estos pueblos. Es en condiciones estructurales de exclusión social y de racismo como los afrodescendientes están enfrentando a la COVID-19. 
La pandemia ha implicado una propagación exponencial del contagio del coronavirus que está afectando globalmente, aunque con intensidades variables, prácticamente a la totalidad de los países de los cinco continentes. ${ }^{1}$ Dadas las dimensiones del fenómeno, la proliferación de informaciones y análisis sobre sus características e impactos también se han multiplicado. En el caso particular de interés en este trabajo, el de las poblaciones afrodescendientes, las fuentes de información también son múltiples. Sin ninguna pretensión de exhaustividad, y teniendo como marco de referencia las condiciones de desigualdad estructural que marcan la situación de los afrodescendientes, el propósito de este estudio es plantear algunas reflexiones a partir de posicionamientos de actores que se están expresando por diversos canales de difusión digital a los que se ha podido tener acceso.

Entre los grupos considerados con mayor vulnerabilidad frente a los embates de la COVID-19, tanto sanitarios como sociales en general, están las poblaciones afrodescendientes. La pandemia llega en un momento que ya es crítico en materia de desigualdades estructurales irresueltas que afectan a los sectores más pobres de la sociedad, así como a los grupos humanos víctimas de múltiples formas de discriminación y de injusticia.

Son variados y disímiles los sectores desde los que se expresan análisis, opiniones y datos sobre la pandemia y sus efectos en los afrodescendientes. Pero más allá de los matices que dichos sectores pueden tener en sus interpretaciones sobre la coyuntura actual y sus antecedentes, todos coinciden en señalar las desigualdades como un elemento transversal que afecta a estos pueblos. Es en condiciones estructurales de exclusión social y de racismo como los afrodescendientes están enfrentando a la COVID-19.

1 Según las estadísticas de la Johns Hopkins University la pandemia ha tocado, en el momento de la revisión final de este escrito (marzo 2021), 192 países, cerca de 120 millones de contagios y causado más de dos millones y medio de fallecimientos. https://coronavirus.jhu.edu/map.html 
Se exponen inicialmente algunos elementos de contexto y antecedentes sobre la caracterización de la crisis estructural de civilización que atravesaba el mundo cuando se declaró la pandemia. Posteriormente, se abordan las condiciones en que se encontraban los afrodescendientes en el marco de dicha crisis estructural. Luego se presentan elementos sobre la pandemia inscrita en el contexto de crisis y, finalmente, los impactos reales y previsibles que está teniendo en estas poblaciones.

Las fuentes principales sobre estos elementos son los discursos de agencias multilaterales, organismos gubernamentales, las vocerías de las ciencias sociales y los movimientos afrodescendientes. De las caracterizaciones, recomendaciones, dispositivos y reivindicaciones que han ido surgiendo a lo largo de esta coyuntura, se pueden desprender algunos elementos de análisis acerca de las perspectivas que comienzan a vislumbrarse en materia de impactos sobre los afrodescendientes, la forma como sus organizaciones la analizan y las perspectivas futuras. La pandemia es un fenómeno en curso y su evolución, así como sus implicaciones en las distintas sociedades tienen aún un alto grado de imprevisibilidad. Aún así, es posible dar cuenta e interpretar los antecedentes estructurales que la precedieron.

Como resultado, se muestran las confluencias en los diagnósticos presentados por diversos organismos multilaterales y el fuerte contraste entre su pertinencia y el débil balance de realizaciones para la superación de las problemáticas estructurales señaladas. Entre las posturas de los movimientos afrodescendientes, la perspectiva son las movilizaciones políticas que pueden confluir con otras voces que están planteando la necesaria transformación del modelo de sociedad. Pero hay que ser precavidos en las interpretaciones de los hechos que están por desarrollarse y que se irán transformando gradualmente por la incidencia de múltiples factores. 


\section{La crisis estructural en la que surge la pandemia de la COVID-19}

En múltiples espacios de análisis y con diferentes acentos existía, desde antes de la llegada del coronavirus, una cierta coincidencia en la interpretación del funcionamiento de las sociedades en una situación de crisis estructural. Dos de los elementos más fuertes en estos diagnósticos sobre el carácter profundo del disfuncionamiento global son: el enorme aumento de las desigualdades de todo tipo con su corolario de discriminaciones y la crisis ambiental.

Entre las discriminaciones ocupa un lugar relevante el racismo, del que una de sus víctimas principales son los afrodescendientes. Esta constatación confirma el fracaso del modelo de desarrollo basado en la preeminencia del mercado y la rentabilidad sin límites, la sobreexplotación de millones de seres humanos, el extractivismo desbordado y sin respeto de las mínimas normas ambientales, y el abandono de políticas redistributivas que privilegien lo social y la vida. Instituciones como la Organización de Naciones Unidas (ONU), el Programa de las Naciones Unidas para el Desarrollo (PNUD), el Comité de Oxford de Ayuda contra el Hambre (OXFAM, por sus siglas en inglés) o World Inquality Database documentan con datos duros esta constatación del nivel que adquieren las desigualdades. ${ }^{2}$

El otro aspecto central es la crisis ambiental, de la cual también es responsable principal el modelo de acumulación capitalista acentuado a su máxima expresión con el neoliberalismo. El mundo entró en una nueva era geológica, el Antropoceno, ${ }^{3}$ que marca la incidencia del ser humano

2 Véase OXFAM (2015, 2018), World Inequality Lab (2018), PNUD (2019), ONU (2020).

3 Svampa (2016) en su artículo "El Antropoceno, un concepto que sintetiza la crisis civilizatoria" hace una revisión de la génesis del concepto y su relación con la crisis estructural del modelo de sociedad. Briones, Lanata y Monjeau (2019), en el artículo "El futuro del Antropoceno" reflexionan sobre los debates que este concepto 
en factores como el calentamiento global, la pérdida de la biodiversidad y el aumento imparable de catástrofes naturales como consecuencia de los impactos de las transformaciones que operan en la naturaleza debido al comportamiento humano. En materia de documentación sobre la dimensión y el impacto de la catástrofe ambiental, son muy relevantes los informes del Grupo Intergubernamental de Cambio Climático (IPCC), creado en 1990 luego del Informe de la Comisión Mundial sobre el Medio Ambiente y el Desarrollo, "Nuestro futuro común” o Informe Brundtland, presentado en la Asamblea General de las Naciones Unidas de 1987. Desde ese momento se han venido sucediendo las diversas iniciativas destinadas a comprometer al conjunto de Estados y sociedades en una rectificación de los patrones de comportamiento en relación con el medio ambiente. Son muy relevantes la Conferencia de las Naciones Unidas sobre el Medio ambiente y el Desarrollo o Cumbre para la Tierra, celebrada en Rio de Janeiro en 1992; la Cumbre Mundial del Desarrollo Sostenible cumplida en 2002 en Johannesburgo; la Cumbre de Río + 20, realizada en 2012 en Rio de Janeiro para hacer un balance de los 20 años transcurridos desde la Cumbre de la Tierra; el trabajo del Grupo Intergubernamental de Expertos sobre el Cambio Climático y su informe de 2014; las conferencias anuales que desde 1995 realiza la Conferencia de las Partes (Conference of Parties-COP); y la Agenda 2030 para el Desarrollo Sostenible lanzada en 2015 por la ONU. ${ }^{4}$ Una buena síntesis de las dimensiones del problema la expresó el Secretario General de la ONU, Antonio Guterres, ante la Cumbre de Naciones Unidas sobre Biodiversidad en 2020:

La emergencia planetaria está sobre nosotros impulsada por las amenazas de la crisis climática y el colapso de la biodiversidad, la vida en el planeta está amenazada. Estamos en guerra con la naturaleza y la naturaleza está

ha generado a la luz de la aceleración de las transformaciones estructurales del planeta.

4 Los objetivos de la Agenda en materia económica, social y ambiental tienen como una de sus premisas la "erradicación de la pobreza" (ONU, 2020). 
contraatacando, los desastres de la biodiversidad están ocurriendo ahora mismo, con derrames de petróleo que están devastando muchos ecosistemas y los incendios forestales que están matando personas y destruyendo hábitats, además de dejar pérdidas económicas incalculables. (Párr. 4).

Todas estas voces de alerta y declaraciones de compromiso representan, a la luz de los resultados de los últimos balances sobre la situación en materia climática, la constatación de un fracaso. Tal vez el concepto de Capitaloceno ${ }^{5}$ sea más preciso para responsabilizar al capitalismo como modelo de sociedad, en cuanto culpable de la catástrofe ambiental a la que las sociedades contemporáneas estamos sometidas. En efecto, el mundo prepandemia se encontraba ya confrontando una confluencia de factores de crisis, que es caracterizada por varios autores como una crisis civilizatoria. ${ }^{6}$ Los graves problemas evocados de las desigualdades y la crisis ambiental están íntimamente articulados a un patrón de modelo de sociedad.

\section{Inmersos en la crisis estructural: los afrodescendientes y el racismo}

La crisis civilizatoria tiene efectos sobre el planeta en su conjunto. Naturaleza y seres humanos estamos confrontados a la agudización de los factores negativos que caracterizan el devenir del mundo. Pero tal como lo evidencia la problemática de las desigualdades, la crisis estructural afecta de forma desproporcionada a los sectores más desfavorecidos de la sociedad, víctimas de múltiples formas de exclusión social y de discriminación. Así mismo, son estos sectores los que enfrentan con mayor grado de vulnerabilidad los efectos del cambio climático, cuando estos se expresan en forma de catástrofes naturales, incendios forestales, sequías, inundaciones, tormentas, huracanes, etc.

5 Noción propuesta por Jason Moore (2017), comentada por Svampa (2016) y Briones et al. (2019).

6 Lander (2019) presenta una buena síntesis de los factores que caracterizan la crisis civilizatoria, y realiza una revisión crítica de la bibliografía sobre el tema. 
Los afrodescendientes hacen parte de estas poblaciones víctimas de primera línea de la crisis estructural que se ha delineado. Pero, ¿cuáles son los factores que determinan esta dura realidad? La jerarquización racial, con el ingrediente principal de la esclavización, fue un factor central en el despegue del capitalismo como sistema económico y de poder político social y cultural. Esta fue antecedida por otro cimiento sustancial de control del poder: el patriarcado. La estructuración de la sociedad en clases dominantes y clases explotadas completa esta trilogía que constituye el basamento de la perpetuación de los mecanismos imbricados de poder que hoy siguen vigentes. Una visión muy esclarecedora de esta situación la aporta el enfoque interseccional que surge desde la teoría feminista y se convierte en un prisma de análisis sobre la forma como las relaciones de poder que caracterizan al patriarcado y el sexismo se articulan con las formas de racismo y de dominación de clase. ${ }^{7}$ Los pueblos afrodescendientes sufren de frente el yugo de estas tres formas de opresión. Los determinantes de raza, clase y género están articulados y se apoyan en mecanismos de orden cultural e ideológico, que conservan de formas explícitas o camufladas jerarquías de valor racializadas, que finalmente hacen de la inferiorización de las "minorías" el sustento de la perpetuación de las relaciones de poder dominantes.

Son muchos los estudios sobre la forma en que el racismo se cruza con la exclusión y la pobreza en poblaciones afrodescendientes. Los diagnósticos nacionales y regionales muestran indicadores sociales negativos. A pesar de que subsisten muchas deficiencias en la obtención de datos desagregados por diferenciación racial en Latinoamérica y el Caribe, las estadísticas existentes sobre acceso a medios básicos como salud, vivienda, agua potable, saneamiento, electricidad, educación, empleo y recreación confirman que las políticas implementadas en dirección a superar estos resultados negativos han fracasado, o en el mejor de los casos muestran resultados muy frágiles. En materia de salud, los diagnósticos de la Organización

7 Las referencias sobre esta temática son múltiples. Una revisión analítica del enfoque interseccional puede verse en Viveros (2016). 
Panamericana de Salud (OPS), avalados por la Organización Mundial de la Salud (OMS), van en la dirección de señalar la vulnerabilidad mayor de los afrodescendientes frente a diversas patologías causadas por la precariedad social, y orientan a planes diferenciales con enfoque étnico para disminuir sus riesgos sanitarios. Sobre el tema ambiental, que está identificado como uno de los pilares de la crisis estructural actual, cabe señalar que los afrodescendientes sufren de frente los impactos de fenómenos naturales y del cambio climático, los cuales afectan de manera directa sus hábitats rurales y urbanos. También, soportan los efectos de problemáticas relacionadas con el control y manejo de los recursos naturales, la biodiversidad, el territorio y las políticas de desarrollo. ${ }^{8}$

Uno de los diagnósticos más recientes es el del Banco Mundial (2018), en el que registra que según los últimos datos demográficos los afrodescendientes representan unos 130 millones de personas, lo que significa el $25 \%$ de la población total de la región; de las poblaciones en situación de extrema pobreza, los afrodescendientes representan el 50\%; y la pobreza afecta a los afrodescendientes con relación a la población total en los siguientes países, en estos porcentajes respectivamente: Colombia $41 \%$ y $27 \%$, Ecuador $34 \%$ y $22 \%$, Brasil $26 \%$ y $12 \%$, y Uruguay $13 \%$ y $4 \%$. El mismo informe muestra el carácter multidimensional de los factores de exclusión social que sufren los afrodescendientes. La Comisión Económica para América Latina y el Caribe (CEPAL), en sus informes de 2017 y 2018, que sirvieron como fuente importante para el Banco Mundial (BM), reconfirma las dimensiones estructurales de la brecha de desigualdades que afecta a estos pueblos (CEPAL/OPS/ UNFPA, 2017). Una actualización de datos y análisis de la CEPAL y el Fondo de Población de las Naciones Unidas (UNFPA) se encuentra en su último informe de octubre de 2020: Afrodescendientes y la matriz de la desigualdad social en América Latina: retos para la inclusión, que incluye elementos en el marco de la pandemia.

8 Ver, entre otros diagnósticos y estudios sobre el tema: PNUD (2010), Telles y PERLA (2014), AFRODESC (2015). 
Para el caso de Brasil, país de América Latina que cuenta con las estadísticas más completas desagregadas por diferenciación racial, las cifras del Instituto Brasilero de Geografía y Estadística, retomadas por Da Silva y Euclides (2020), ilustran bien las dimensiones de la desigualdad de la población negra: $55.8 \%$ del total, $54.9 \%$ de la fuerza laboral, desempleados $64.2 \%$ y empleos precarios $66.1 \%$. El $75.2 \%$ de los salarios más bajos son para los afrobrasileros y del $10 \%$ de los salarios más altos solo el $27.7 \%$ de los afrobrasileros acceden a ellos. En promedio, las mujeres negras reciben solo el $44 \%$ de los ingresos de sus congéneres blancas y los hombres negros solo el $56.1 \%$ de lo que reciben los hombres blancos. La población blanca tiene ingresos $45 \%$ más altos que la población negra con el mismo nivel de formación. En 2018, más de 6 millones de personas se ocupan en trabajo doméstico; de estas 5.7 millones son mujeres y 3.9 millones (68.4\%) de ellas son mujeres negras.

La violencia es otra faceta a través de la cual se expresa el racismo contra los afrodescendientes. El caso de los Estados Unidos es el más evidente, como lo muestra la historia larga y un presente colmado de casos de asesinatos de afroamericanos, mayoritariamente a manos de fuerzas policiales. Es relevante la importante respuesta de movilización antirracista que ha generado el movimiento Black Lives Matter (La vida de los negros importa). Las imágenes que recorrieron el mundo con ocasión del asesinato de Georges Floyd por un policía, el 25 de mayo de 2020 en Minneapolis, activaron una fuerte respuesta de movilización y rechazo en los Estados Unidos y en otros países. A nivel global se multiplicaron los actos de apoyo al movimiento, pero también fueron la ocasión para agitar denuncias de actos de violencia racista que se presentan en otros países. En América Latina también se registran formas de violencia ejercida contra los afrodescendientes. El caso de Brasil es el más representativo. Apoyado en cifras del Foro Brasileño de Seguridad Pública, Arturo Wallace (2020) informa que ocho de cada diez víctimas de asesinatos en Brasil son afrodescendientes. En 2018, el 75.4\% de 
los 6220 asesinatos policiales fueron afrobrasileros. ${ }^{9}$ En Colombia los afrodescendientes son uno de los grupos de población más golpeados por los desplazamientos forzados y los asesinatos perpetrados por bandas criminales, en un contexto de búsqueda de control territorial y despojo. El pueblo afrodescendiente garífuna de Honduras también denuncia persecuciones y asesinatos en el marco de su movilización por sus territorios. Los derechos territoriales de los afrodescendientes, que han sido reconocidos institucionalmente en estos tres países, son vulnerados de múltiples formas y la violencia por diversos actores armados es uno de los medios utilizados para conculcarlos. ${ }^{10}$ En varios países de la región se señalan las políticas de perfilamiento racial con las que operan la policía y los aparatos de justicia. En este marco ha surgido, de parte de un grupo de organizaciones de derechos humanos y movimientos sociales, una iniciativa para solicitar una audiencia ante la Comisión Interamericana de Derechos Humanos (CIDH) para hablar sobre violencia policial y el racismo institucional contra personas afrodescendientes en las Américas. Esta iniciativa documenta denuncias que conciernen a las poblaciones afrodescendientes en Argentina, Bolivia, Brasil, Colombia, Honduras, República Dominicana, Guyana, Panamá, Perú y Estados Unidos. ${ }^{11}$

Entre los espacios que han jugado un papel de referencia en el proceso de caracterización de las formas de racismo y exclusión contra los afrodescendientes es importante mencionar la Conferencia Mundial contra el Racismo, la Discriminación Racial, la Xenofobia y Formas Conexas de Intolerancia, organizada por las Naciones Unidas y realizada en Durban, Sudáfrica, en septiembre de 2001. Este evento fue un punto de inflexión muy importante que marcó un nuevo nivel de organización de los pueblos afrodescendientes, así como el reconocimiento de sus

9 Para un análisis a fondo sobre la violencia contra la población negra en Brasil, véase Alves (2018).

10 La situación está ampliamente documentada. Véase, para el caso de Honduras, Loperena (2017) y Agudelo $(2018,2019)$; para Colombia, Duarte et al. (2020); y para Brasil, CONAQ (2018).

11 Global Human Rights Clinic (s.f.). 
reivindicaciones, fundamentadas en una fuerte denuncia sobre las diversas formas que asumía el racismo y la exclusión. La Conferencia fue precedida de la Preconferencia de las Américas contra el Racismo, realizada en Santiago de Chile en el año 2000. Estos dos eventos contaron con la presencia de representantes de los gobiernos latinoamericanos y del Caribe, quienes se comprometieron a adoptar las orientaciones emanadas de la Conferencia como garantía de superación de los factores de exclusión y racismo que afectaban a los afrodescendientes. Diez años después la ONU declaró al 2011 Año Internacional de los Afrodescendientes, y en 2014 se decretó el Decenio Internacional para los Afrodescendientes (2015-2024). Todo esto intercalado con múltiples foros, encuentros, seminarios, elaboración de informes por diversos organismos del sistema de Naciones Unidas y de otras agencias multilaterales a los que se ha hecho alusión. A pesar de los logros en materia de reconocimiento de derechos en el contexto de políticas multiculturales que se han ido implementando en la región desde los años 1990, los resultados en materia de superación del racismo estructural y sus secuelas de exclusión muestran claramente sus límites. El balance de los avances del decenio es deficiente (Campoalegre, 2017). Los compromisos de la Conferencia de Durban siguen agitándose como un objetivo a alcanzar, pero el entronque de las múltiples facetas y su interconexión con los demás elementos de la crisis estructural parecieran un obstáculo infranqueable, si no se presentan alternativas que impliquen transformaciones fundamentales del modelo de sociedad actual (Agudelo, 2019a).

\section{La pandemia, un hecho social total resaltador de la crisis estructural}

La consideración de la pandemia de la COVID-19 como un hecho social total, ${ }^{12}$ desde el punto de vista antropológico y sociológico parece

12 Ignacio Ramonet hizo alusión a este concepto en su difundido ensayo Ante lo desconocido... La pandemia y el sistema-mundo. El origen de esta herramienta de interpretación de los hechos sociales es el antropólogo francés Marcel Mauss, a 
pertinente. Sus implicaciones a escala planetaria conciernen el conjunto de interacciones sociales en grados diversos: los campos de la salud, la economía, la cultura, la geopolítica, el medioambiente, las instituciones, las normas, las relaciones de poder, los valores. No hay dominio de lo social que no sea concernido por su impacto. Es un hecho global que está cambiando la vida de miles de millones de personas, cuyos efectos en el futuro comienzan a preverse y son objeto de cientos de diagnósticos y prospectivas con niveles importantes de incertitud. Desde su inicio en Wuhan, China, en enero de 2020, en el actual contexto, la COVID-19 se transformó rápidamente en pandemia tocando la mayoría de los países del mundo, aunque en grados diversos. ${ }^{13}$ De la conmoción por la propagación de los contagios se derivó rápidamente a las dificultades enfrentadas por los sistemas sanitarios y las falencias en el acceso a los cuidados para millones de personas, debido a sus condiciones de pobreza o la precariedad de los servicios de salud pública. Y en el marco de las políticas adoptadas en la mayoría de los países para contener la pandemia, rápidamente comenzaron a sentirse las consecuencias económicas, que también han tenido efectos diferenciados golpeando más intensamente a los países pobres y a las poblaciones vulnerables de todo el mundo.

Al conteo diario de contagios, fallecimientos y tasas de morbilidad y mortalidad se multiplican los diagnósticos sobre el desastre económico global, en la medida que la pandemia se extiende en el tiempo. Para el Banco Mundial (2020b) se trata de la recesión económica más importante desde que estas mediciones se realizan. La contracción de la economía llevará a más de 350 millones de personas a la pobreza y a más de 100 millones a la pobreza extrema (Banco Mundial, 2020a). Pero si para la economía global los diagnósticos son negativos, el panorama se

partir de sus investigaciones sobre el don y su implicación en sociedades arcaicas (1973).

13 Las múltiples conexiones de transporte de personas y productos que ligan a la China con centros estratégicos de la economía global, y seguidamente con el resto del mundo, explican la rápida expansión del virus y su transformación en pandemia. 
ensombrece todavía más en materia de la brecha de las desigualdades que la pandemia está generando.

En los países donde la economía informal representa la parte sustancial de las actividades con las que tratan de subsistir la mayoría de sus poblaciones, en el contexto de las desigualdades implícitas a la crisis estructural, las medidas de confinamiento reconocidas como un mecanismo eficaz de protección no pueden simplemente aplicarse a cabalidad. Se trata del dilema entre contagiarse del coronavirus o no comer. Las viviendas insalubres, el difícil acceso a servicios de agua y las condiciones de hacinamiento que padecen millones de pobres hacen que las necesarias medidas sanitarias de distanciación, aseo permanente de manos, uso de mascarillas, etc., se vuelvan casi utópicas. La precariedad e insuficiencia en los sistemas de salud también se ha hecho palpable, inclusive en varios países ricos. La pandemia ha evidenciado cómo la salud ha sido uno de los sectores de servicios básicos más golpeados por las políticas de desmonte de los sistemas públicos asumidos por el Estado que ha implicado el giro neoliberal del capitalismo.

Valenti (2020) recoge datos de la Organización Mundial del Trabajo (OIT), de la Organización de las Naciones Unidas para el Desarrollo Industrial (ONUDI), del BM y la CEPAL para mostrar las dimensiones que toman las desigualdades en materia laboral, fiscal, de producción e ingresos. Pero también establece el contraste con el aumento de las ganancias de algunos pocos grupos económicos vinculados a industrias de alta tecnología y comercio electrónico. Su artículo muestra cómo los principales emprendimientos de contención de la crisis los están asumiendo los gobiernos, pero las grandes corporaciones financieras e industriales están ausentes de estos esfuerzos.

Es interesante constatar el papel protagonista del Estado en esta coyuntura. En las iniciativas por intentar salvar la economía de los países y tapar los huecos en los sistemas de salud, son los gobiernos quienes han desplegado con mayor o menor intensidad y eficacia los mecanismos 
de financiamiento, subsidios, auxilios, ayudas extraordinarias, etc. El politólogo francés Bertrand Badie (2020), en una entrevista sobre esta temática, responde así la pregunta sobre el giro keynesiano que de repente impregna los discursos de los políticos más conocidos por su orientación neoliberal:

Es necesario recordar que lo social ha sido asesinado por el neoliberalismo y relegado a un mero efecto de goteo. La famosa fórmula tan alabada por el Banco Mundial de que 'el crecimiento es bueno para los pobres' porque acabarán beneficiándose de sus efectos, refleja la manera en la que se ha concebido lo social en los últimos 30 años. Si hoy los profetas del neoliberalismo se están convirtiendo en promotores de la economía social es porque conciben, ante la catástrofe actual, que ya no será posible hacer lo mismo que antes y que será necesario volver a los imperativos sociales.

Manuel Castels (2020, p. 103) también plantea que la alternativa para enfrentar la pandemia en curso y el futuro no es otra que un retorno con fuerza del Estado, a través del estímulo a la producción y a una fiscalidad fuerte de los sectores en los que se concentra "el $75 \%$ de la riqueza mundial, a saber, los mercados financieros globales y las grandes multinacionales evasoras legales de impuestos precisamente por su movilidad fiscal y su manejo de los entramados legales”.

Pero las políticas de austeridad y ajuste acechan esperando el momento de retornar con fuerza. Alejandro Werner (2020) advierte que, a pesar de estar desembolsando fondos extraordinarios de emergencia para contribuir con los Estados en sus esfuerzos de recuperación, no se puede tratar sino de medidas transitorias.

Por lo pronto, el balance que se hace de lo que va corrido de la pandemia y las perspectivas que se avizoran es, en general, muy crítico. Los datos que van aportando la multiplicidad de diagnósticos producidos tanto por las agencias multilaterales como por los diversos organismos independientes acerca de los impactos de la pandemia en la sociedad 
van generando discursos de cierta homogeneidad en el reconocimiento de las dimensiones de la problemática. Es relevante reseñar los planteamientos de Luis Almagro, secretario general de la OEA, en el prólogo de la Guía práctica de respuestas inclusivas y con enfoque de derechos ante el COVID-19 en las Américas:

Esta pandemia nos afecta directa e indirectamente a todos. Sin embargo, para las personas en situaciones de vulnerabilidad el alcance del impacto, más allá del acceso limitado, o a veces nulo, a la atención médica, bienes y servicios, es mucho más profundo; y podría, muy probablemente, aumentar las brechas en su acceso a sus derechos económicos, sociales y culturales básicos, considerando que estos grupos de personas son víctimas de discriminación múltiple e interseccional, y que estas discriminaciones se exacerban en situaciones de crisis como la actual. Nos referimos a aquellos que son pobres y marginalizados, muchos de los cuales también pertenecen a otros grupos en situaciones de vulnerabilidad, como los pueblos indígenas, afrodescendientes, personas mayores, personas con discapacidad, migrantes, refugiados y personas LGTBI, niñas, niños y adolescentes y mujeres. Las múltiples e interseccionales discriminaciones que se han naturalizado en nuestros países limitan su acceso y goce de derechos básicos, y en condiciones de emergencia, esta limitación y exclusión se agrava. Como resultado, su capacidad de sobrevivir a la pandemia es mucho menos probable. Se debe poner el énfasis en estas poblaciones que deben tener un apoyo especial porque su condición genera aún más retos para enfrentar la situación, especialmente aquellos que sufren de la inequidad, la de género y de acceso a derechos económicos y sociales. (p. 6)

\section{Impacto de la pandemia en los afrodescendientes}

La declaración del secretario general de la OEA que se acaba de citar sirve de puente para enfocarnos en el caso específico de las poblaciones afrodescendientes. Como se ha señalado anteriormente, las desigualdades históricas y el racismo como problemáticas estructurales hacen de estos pueblos un grupo humano altamente vulnerable frente a los 
embates de la pandemia. Los efectos se hacen sentir no solamente en el dominio de la salud, sino también en materia económica.

Desde los primeros meses de la pandemia se comenzaron a "prender las alarmas" acerca de los graves efectos que ella podría tener sobre los afrodescendientes. De nuevo organismos multilaterales, agencias de cooperación y otras instituciones internacionales se han pronunciado al respecto. Uno de los primeros elementos comunes de algunas de estas declaraciones fue la urgencia de que los gobiernos de la región implementaran un enfoque diferencial en las medidas a adoptar para la contención de los efectos de la pandemia entre los afrodescendientes y los grupos étnicos en general. Judith Morrison (2020) y expertos en derechos humanos de la ONU, a partir del reconocimiento de los problemas de precariedad y desigualdad con la que los afrodescendientes se enfrentan a la pandemia, reclaman la urgencia de contar con datos desagregados para medir con precisión los impactos de la pandemia entre estas poblaciones.

La Red Interamericana de Altas Autoridades sobre Políticas de Población Afrodescendiente (RIAFRO), organismo consultivo de la OEA, llama a los gobiernos de la región a tomar en cuenta las recomendaciones emitidas por la OPS (2020) en materia de salud y etnicidad y a seguir la Guía práctica de respuestas inclusivas y con enfoque de derechos ante el COVID-19 en las Américas de la OEA (2020). Algunos gobiernos crearon directivas para implementar medidas con enfoque diferencial para el tratamiento de los impactos de la pandemia entre poblaciones indígenas y afrodescendientes. Son conocidos los casos del Ministerio de Salud de Colombia (2020) y del Ministerio de Salud Pública de Costa Rica (2020). Wellenstein, González y Freire (2029), en el blog del BM reivindican la validez de sus diagnósticos en la grave situación de exclusión y desigualdad de las poblaciones afrodescendientes que se acentúan en el contexto de la pandemia y llaman a los países de la región a "establecer estándares más altos para llegar a comunidades históricamente excluidas" (párr. 7). En esa misma dirección se manifiestan la Comisión 
Interamericana de Derechos Humanos (2020), el UNFPA (2020) y el PNUD (2020). El Grupo de Trabajo de Expertos de las Naciones Unidas sobre Afrodescendientes ${ }^{14}$ recomienda a los Estados a implementar políticas de equidad racial que implican contar con directivas específicas de urgencia, dirigidas hacia estas comunidades en el marco de la pandemia. En su declaración el Grupo presenta un informe sobre patologías preexistentes entre los afrodescendientes, que los hacen más vulnerables frente al coronavirus: hipertensión, diabetes, obesidad, enfermedades cardiovasculares. También señala sus formas precarias de hábitat, el hacinamiento y las dificultades de acceso a servicios públicos, como otros factores de riesgo acentuado frente a la pandemia. Llama la atención acerca de la sobrerrepresentación de los afrodescendientes entre los sectores sociales vinculados a la economía informal o a los sectores básicos en transportes, servicios públicos, producción y comercio de alimentos, servicios auxiliares de salud que han estado expuestos de forma permanente a mayores posibilidades de contagio del virus y que no han tenido condiciones para adoptar las medidas de confinamiento y distanciamiento recomendadas como mecanismo de protección y disminución del riesgo de contagio. El Grupo encuadra estas falencias en el marco de la "discriminación racial estructural" que agudiza disparidades en materia de salud, y que se hacen más palpables en la actual situación de emergencia sanitaria y social.

Es de notar que, en general, se trata de las mismas instituciones internacionales a las que se viene haciendo referencia en relación con los diagnósticos sobre las desigualdades estructurales, la exclusión y el racismo que preceden a la pandemia de la COVID-19, problemáticas a las que son confrontadas las poblaciones afrodescendientes. De hecho, las argumentaciones actuales se apoyan en sus consideraciones anteriores a la coyuntura. Existe una especie de saturación en la caracterización

14 Este Grupo surgió en 2002 luego de la Conferencia de Durban. Hace parte de los "Procedimientos Especiales" del Sistema de Derechos Humanos de Naciones Unidas. Son expertos independientes que presentan recomendaciones. 
de las causas y los impactos, pero sigue quedando pendiente el tránsito hacia la implementación de los múltiples llamados y recomendaciones a los Estados en materia de políticas públicas que contribuyan a la superación de estos problemas de orden estructural, que actualmente se potencian en medio de la pandemia. Pero también está en curso un debate acerca de los mecanismos más eficaces para obtener resultados tangibles frente a los problemas de orden estructural que aquí se han señalado. En este contexto, desde la orilla de los movimientos afrodescendientes se dejan oír algunas voces que van más allá de la exigencia de reivindicaciones precisas en el marco de la pandemia, y de las agendas ya conocidas y sintetizadas en los compromisos de la Conferencia de Durban o de los objetivos del Decenio Internacional de los Afrodescendientes, de Naciones Unidas.

\section{Voces afrodescendientes}

A continuación se presentan algunos ejemplos de las posiciones que desde el movimiento afrodescendiente se están expresando tanto en relación con los impactos de la pandemia y alternativas para confrontarlos como frente a perspectivas de largo plazo en el terreno de enfrentar los factores estructurales que caracterizan la situación de estos pueblos.

La coyuntura de la pandemia ha incrementado la presencia de los movimientos afrodescendientes en las redes de difusión digital. La plataforma virtual del Consejo Latinoamericano de Ciencias Sociales (CLACSO) ha sido un instrumento eficaz de difusión de las denuncias y reivindicaciones de movimientos afrodescendientes en Latinoamérica y el Caribe en esta coyuntura. Su trabajo de promover los intercambios académicos y del activismo social y político afrodescendiente ya tiene varios años de trayectoria. Resalta la labor de sus grupos de trabajo "Afrodescendencias y propuestas contrahegemónicas" y "Crisis civilizatoria, reconfiguraciones del racismo, movimientos sociales afrolatinoamericanos". Frente a la problemática de los impactos de la pandemia para los afrodescendientes, la serie de boletines periódicos de los grupos de trabajo 
La pandemia racializada. Debates desde la afroepistemología I, II y III y el boletín Polifonía por la vida: de la coronacrisis a la primavera de ébano (2020d).

Se trata de la articulación entre resultados de investigación crítica, análisis y activismo. Aunque hay una variedad de expresiones, en general coinciden en una visión antisistémica y una crítica de fondo al racismo estructural. Este es el marco en el que se ubican las posturas expresadas sobre la pandemia.

Sobre el diagnóstico de los efectos que está teniendo la pandemia entre los afrodescendientes, se coincide en general con los planteamientos de las agencias multilaterales y otras instituciones que se han presentado arriba. Igualmente, en dejar sentado que son las condiciones críticas estructurales que caracterizan a estos pueblos los factores que explican una mayor vulnerabilidad. En el aspecto en que sí se encuentra una diferencia sustancial es en la formulación de propuestas estratégicas de transformación del modelo de sociedad como alternativa más allá de la superación de los problemas que se están enfrentando actualmente con la pandemia. Entre los países de la región en los que se puede observar una mayor difusión de las actividades de sus movimientos afrodescendientes se encuentran los casos de Colombia, Brasil y Honduras.

Según mi observación, el movimiento afrodescendiente colombiano con más difusión de sus actividades en las redes digitales en relación con la pandemia es RENACIENTES Proceso de Comunidades Negras (PCN). ${ }^{15}$ También son relevantes las publicaciones de la Conferencia Nacional de Organizaciones Afrocolombianas (CNOA). ${ }^{16}$ En marzo de 2020, el Consejo Nacional de Paz Afrocolombiana (CONPA), que es una red a la que están vinculados el PCN, la CNOA y otros movimientos afrocolombianos lanzó sus Directrices para responder al COVID-19

\footnotetext{
15 https://renacientes.net/

16 https://convergenciacnoa.org/
} 
para el pueblo y comunidades afrodescendientes en Colombia. En este documento, además de reafirmar la denuncia sobre las condiciones de racismo estructural que hacen de los afrocolombianos una población altamente vulnerable frente a la pandemia, también exigen al Gobierno la implementación de políticas diferenciadas en materia sanitaria y de respuesta al impacto económico. Finalmente hacen una serie de recomendaciones sobre cuidados a las comunidades y llaman la atención sobre la continuidad en medio de la pandemia de los asesinatos de líderes sociales y de pobladores afrodescendientes.

En agosto 2020, el PCN difundió el informe Situación del pueblo negro, afrodescendiente, raizal y palenquero en Colombia en el marco del COVID-19. Aprendizajes y desafíos, que es presentado así:

El Proceso de Comunidades Negras en Colombia PCN, en articulación con otras organizaciones de base y Consejos Comunitarios, desde el inicio de la pandemia nos dimos la tarea de establecer diferentes mecanismos que permitieran hacer un monitoreo específico de las repercusiones que el COVID-19 ha tenido en nuestras comunidades y territorios, de manera que se puedan tener indicadores no solo de contagios, sino cómo este ha incidido desde diferentes escenarios en las formas de vida, los medios de producción tradicionales, las relaciones ancestrales, familiares y comunitarias y la agudización de las condiciones de vida causadas por el racismo estructural. Así mismo, se establecieron mecanismos de relacionamientos directos con las comunidades, por medio de los cuales se ha venido monitoreando el avance del contagio, especialmente en las veredas de los Consejos comunitarios con presencia mayoritariamente de comunidad negra. (2020, p. 1).

El informe desglosa por regiones los siguientes puntos: 1- Amenazas comunitarias, desplazamiento forzado, movilidad territorial, secuestros y presencia de grupos armados. 2- Violencia de género e intrafamiliar. 3- Mitigación de riesgos (sabiduría ancestral-salud pública y control territorial autonomía). 4- Control de acceso al territorio (Guardia cimarrona). 5- Uso de medicina ancestral. 6- Estudio de expedición de decretos 
y afectaciones a las comunidades negras (en el marco del COVID). 7Soberanía alimentaria, abastecimiento y comercialización de productos. 8- Movilidad comunitaria. 9- Educación y conectividad. 10- Otras dificultades reportadas en las regiones. Este documento permite tener una visión panorámica de la situación en el caso colombiano. ${ }^{17}$

Para el caso de Brasil es relevante el documento producido en el 2020 por la Coalición Negra por Derechos (Coalização Negra por Direitos), en el que luego de llamar la atención sobre las duras condiciones en las que los afrobrasileros comenzaban a sentir el impacto de la pandemia (marzo 2020), hace una serie de exigencias al Estado: 1- Adopción de medidas de protección de las poblaciones negras y otros grupos afectados o vulnerables frente al COVID-19. 2- Cuidados especiales a las personas contagiadas. 3- Medidas de prevención, atención y salud. 4- Asistencia social. Otro pronunciamiento de interés que proporciona elementos del contexto político y social en que llega la pandemia a Brasil y su impacto sobre las poblaciones negras se encuentra en Salvar vidas y garantizar derechos de la población negra, de la Coordinación Nacional de Entidades Negras (CONEN). Su presentación plantea:

Son diversos los posicionamientos y manifiestos proponiendo salidas y alternativas para enfrentar el grave momento que estamos viviendo en Brasil y en el mundo. Uno de los más importantes por su densidad propositiva, política y construcción unitaria es la "Plataforma de emergencia para enfrentar la pandemia del Coronavirus y de la crisis brasileña”, construido por los Frentes Brasil Popular y Pueblo sin Miedo, partidos políticos del campo democrático y popular, centrales sindicales, movimientos populares y estudiantiles, organizaciones democráticas de la sociedad brasileña.

17 El monitoreo realizado por el PCN tiene sus límites en la cuantificación de los impactos sanitarios de la pandemia entre las comunidades negras. Una propuesta metodológica de medición se encuentra en Duarte et al. (2020). 
Además de su carácter de emergencia y específico —el combate al coronavirus - esa Plataforma amplía el debate sobre la necesidad de un proyecto en condiciones de promover, de hecho, reformas estructurales y las transformaciones necesarias en la sociedad y en la vida de los brasileños y brasileñas. La CONEN - Coordinación Nacional de Entidades Negras, contribuyó con la elaboración y firma de esa Plataforma. Sin embargo, con este documento, llama la atención de los signatarios de la Plataforma sobre quien son los principales afectados en Brasil por el coronavirus y sus consecuencias económicas.

Para la CONEN y el movimiento negro brasileño, a pesar de nuestros avances y conquistas recientes, que el gobierno de Bolsonaro intenta destruir, continuamos viviendo en un país donde las desigualdades raciales, regionales, de clase, de género y generacionales aún son inmensas. ¡Brasil continúa siendo un país muy desigual! (CONEN, 2020, p. 3).

El documento contiene una detallada compilación de datos cuantitativos analizados, que muestran claramente la dimensión de las desigualdades económicas y sociales de los afrobrasileros y su situación para afrontar la pandemia de la COVID-19.

Para el caso de Honduras, las dos principales organizaciones garífunas del país, la Organización Fraternal Negra Hondureña (OFRANEH) ${ }^{18}$ y la Organización de Desarrollo Comunitario (ODECO) ${ }^{19}$ han mantenido iniciativas de intervención hacia sus comunidades a través de sus redes de difusión y mediante el activismo local, y son los movimientos más sólidos de afrodescendientes en Centroamérica. También es notable la labor de difusión de información sobre el impacto de la pandemia entre los garífunas hondureños, de la red de noticias Wadani. ${ }^{20}$ Las dos organizaciones han desplegado un importante trabajo

18 http://ofraneh.org/ofraneh/index.html

19 http://odecohn.blogspot.com/

20 https://wa-dani.com/ 
comunitario de orientación y apoyo sobre cuidados y otras medidas de protección, en el marco de las condiciones de precariedad en que vive la mayoría de su población. Asímismo, mantienen planteando exigencias al Estado en materia de asistencia y fortalecimiento de la infraestructura de salud, casi inexistente en las regiones costeras habitadas por este pueblo, de lo que es ejemplo el mensaje de Miriam Miranda (abril, 2020), principal dirigente de OFRANEH. En materia de defensa de sus derechos territoriales, objetivo fundamental de OFRA$\mathrm{NEH}$, paralelamente con el impulso de las medidas de cuidado comunitario frente a la COVID-19 esta organización ha mantenido una denuncia muy fuerte de los casos de agresiones y violación de los derechos humanos de las comunidades. ${ }^{21}$

Finalmente, una de las redes más activas en la generación de posicionamientos frente a la coyuntura actual, con una perspectiva crítica antisistema, ha sido la Articulación Regional de Afrodescendientes de las Américas y el Caribe (ARAAC). ${ }^{22}$ Hacen parte de esta organización movimientos afrodescendientes de varios países de la región. En su manifiesto Crisis civilizatoria, pandemia y racismo, se pronuncia frente a la actual pandemia y sintetiza los elementos centrales de sus objetivos reivindicativos y de transformación del modelo de sociedad que caracteriza dicha crisis. Estos son algunos apartes del manifiesto:

Impulsar la organización de base en nuestros territorios y comunidades, centros de trabajo, y espacios de movimiento, para cultivar el cuidado colectivo, la educación popular para promover la reflexión crítica para comprender mejor este momento, y la acción colectiva para nuestro bienestar como pueblos negros, en alianza con todos los sectores sociales afectados por la crisis y así potenciar sus posibilidades transformadoras.

21 Ver arriba en la sección sobre la forma como la violencia afecta las poblaciones negras en Latinoamérica.

22 https://www.facebook.com/ARAAC.afrodescendientes/?ref = page_ internal\&path $=\% 2$ FARAAC. afrodescendientes $\% 2 \mathrm{~F}$ 
2. Demandar servicios y bienes básicos, sobre todo para las personas más vulnerables, como las que carecen de seguridad social, vivienda, cuidado de salud, y trabajo estable, entre las cuales, las/los Afrodescendientes estamos sobrerrepresentados. Esto implica garantías de seguridad alimentaria, de ingresos mínimos, de salud pública, y vivienda. Los estados tienen la responsabilidad principal de elaborar e implementar medidas de política pública que garanticen la vida y el bienestar colectivo, sobre todo el cuidado de salud, ingresos mínimos, salario social y vivienda.

No buscamos volver a una supuesta normalidad sino transformar de raíz el orden mundial en que vivimos. El balance ecológico del planeta y la vida misma está en peligro. Los pueblos afrodescendientes e indígenas somos portadores y custodios de la Madre Tierra. Tocando ese tambor llamamos a la defensa del agua dulce, la soberanía alimentaria, el equilibrio climático, y la armonía ecológica y espiritual entre todos los seres vivos. Abogamos por la construcción colectiva de un mundo mejor, fundamentado en la armonía ecológica, la equidad étnico-racial y de género, el respeto a la diversidad sexual, el comunitarismo, la solidaridad humana, y la justa redistribución de riqueza y poder. En su conjunto, estos principios nos definen como movimiento afrodescendiente de carácter radical y progresista. (ARAAC, 2020, pp. 8-9). ${ }^{23}$

En esta perspectiva de radicalización del discurso reivindicativo de los afrodescendientes, a partir de estudios realizados en siete países de la región, incluyendo los Estados Unidos, recientemente se ha publicado el libro Black and Indigenous Resistance in the Americas: From Multiculturalism to Racist Backlash, obra en la que Juliet Hooker (2020) muestra un incremento del racismo y también de la movilización antirracista, ubicando al capitalismo como responsable de la crisis de sociedad en la que se manifiesta la situación crítica de las poblaciones negras. Igualmente, revela la búsqueda de ir más allá de los reclamos en el marco de la institucionalidad multicultural y plantearse alternativas de transformación

23 https://www.clacso.org/en/boletin-1-nuestra-afroamerica-crisis-afrodescendientes-movimientos/ 
del modelo de sociedad, con una perspectiva interseccional que articule problemáticas raciales, de género y de clase en las que confluyan con otros sectores sociales.

En efecto, un elemento común a los discursos de los movimientos afrodescendientes que se han presentado en los casos de Colombia, Brasil, Honduras y en la red ARAAC, es el de estar articulados con otros frentes de lucha que coinciden en el cuestionamiento del modelo de sociedad predominante. La pandemia es vista no solo como un factor de riesgo e impacto negativo para los afrodescendientes, sino también como una posibilidad de potenciar los niveles de movilización.

\section{Seguir pensando la pandemia y sus impactos entre los afrodescendientes}

La pandemia por COVID-19 ha desnudado nuestras fragilidades y constituye un hecho global que ha revelado la insostenibilidad de un estilo de desarrollo sustentado en la profundización de las desigualdades, la extensión de la precariedad de la reproducción social, la destrucción ambiental y el debilitamiento del multilateralismo y la cooperación internacional.

(...) es momento de discutir los fundamentos de un nuevo régimen de acumulación, de un régimen de bienestar y protección social distinto, de un nuevo acuerdo ambiental global y de una gobernanza mundial consistente con los desafíos que enfrentamos como especie y como planeta. (CEPAL, 2020, p. 9).

Estas reflexiones del representante de la CEPAL para América Central sirven para volver sobre un aspecto que llama la atención al hacer la revisión de las posiciones de este tipo de instituciones y agencias internacionales. Hay un reconocimiento de las dimensiones de la crisis, y de los efectos en curso y en perspectiva de la pandemia. Igualmente, en lo que respecta al caso específico de los afrodescendientes, se observa una especie de consenso en los diagnósticos. La paradoja sigue siendo la 
brecha entre la justeza de estos discursos y la implementación práctica de las medidas que se deberían poner en funcionamiento en materia de resolución de los problemas evidenciados.

Las necesarias transformaciones que se desprenden como respuesta a las múltiples dimensiones de la crisis y sus declinaciones en el contexto actual de la pandemia deben ubicarse en el terreno de una confrontación política. Hasta el presente la correlación de fuerzas no ha sido favorable a los campos que reivindican los cambios urgentes en el modelo actual de sociedad. El peso enorme de las políticas neoliberales que han potenciado los grandes intereses del capital por encima de las urgencias en materia de redistribución y ambientales han bloqueado las posibilidades de cambio.

Para algunos sectores es justo este momento crítico e inédito que atraviesa la humanidad una posibilidad de encaminar la sociedad hacia las transformaciones necesarias en materia ambiental, de desigualdades y discriminaciones. En esa perspectiva se ubican iniciativas como la lanzada desde Francia, "Il est temps de ne pas reprendre"24 (Es tiempo de no recomenzar), en el sentido que la desaceleración de la economía y la producción causada por las medidas tomadas para contener la pandemia, son un momento favorable para replantear el modelo actual que ha llevado al planeta a una crisis ambiental de grandes dimensiones. Esta propuesta se apoya en los análisis y reflexiones de Bruno Latour (2015, 2017). En América Latina surgió la propuesta "Por un pacto social, ecológico, económico e intercultural para América Latina”, impulsada por el grupo promotor del Pacto Ecosocial del Sur. Esta iniciativa se plantea como objetivo:

(...) construir dinámicas sociales capaces de responder a (y contrarrestar) las dinámicas de reacomodo capitalista, concentración de riqueza y destrucción de ecosistemas que vemos surgir en medio de la crisis del

24 https://atecopol.hypotheses.org/4079 
COVID-19 (...) construir, conjuntamente con quienes deseen juntarse, un horizonte colectivo de transformación para Nuestra América que garantice un futuro digno. (Pacto Ecosocial del Sur, 2020, párr. 2).

Estas propuestas expresan el rechazo de un retorno a la "normalidad" que significa la continuidad de la situación de crisis estructural en que se encontraba el mundo antes de la pandemia. En general, la postura de los gobiernos y de los poderes económicos se ubica justamente en el plano de lograr recuperar esa normalidad perdida. Los planes de relanzamiento de la economía y lo que se avizora de parte de los Estados y de los organismos financieros internacionales como el FMI y el BM es la búsqueda de recuperación económica con las grandes ayudas para las áreas estratégicas de la economía capitalista, esto es, la industrial y financiera. Sin embargo, los impactos de fondo en las economías todavía están en curso y no hay certezas sobre las posibilidades de retorno a una "normalidad" que, de todas formas, estará marcada por el impacto de esta crisis sin precedentes. Si bien es cierto que el "golpe al capitalismo a lo Kill Bill”, que anunciaba Slavoj Zizek (2020), no parece tan contundente, los datos sí muestran que el impacto lo sacude. Debatirse entre el retorno a la "normalidad" y las posibilidades de transformación necesarias para revertir la crisis a partir de una ruptura con el actual modelo es el terreno central de confrontación.

En este campo de luchas es donde se ubica la situación actual de los afrodescendientes y las movilizaciones que sus organizaciones están impulsando. Las luchas antirracistas han tenido un despliegue importante en medio de la agudización de la crisis que está significando la pandemia. Las experiencias de movilización aquí presentadas se orientan a la búsqueda de confluencias en una disputa de fondo por transformaciones del modelo de sociedad, articuladas con la permanencia de sus reivindicaciones específicas. 


\section{Referencias}

Afrodescendants et esclavages : domination, identification et héritages dans les Amériques (15ème-21ème siècles) - AFRODESC. (2015). Recuperado de: https://halshs.archives-ouvertes.fr/halshs-01104672/document

Agudelo, Carlos. (2018). Construcción de identidades y territorio en un contexto de movilidad. El caso de los Garífuna, 'Peregrinos del Caribe'. In Odile Hoffmann y Abelardo Morales (Coords.), El territorio como recurso: movilidad y apropiación del espacio en México y Centroamérica. San José: Facultad Latinoamericana de Ciencias Sociales/Laboratorio Mixto Internacional/Institut de recherche pour le développement/ Universidad Nacional de Costa Rica.

Agudelo, Carlos. (22 de junio de 2019a). Paradojas de la inclusión de los afrodescendientes y el giro multicultural en América Latina. Cuadernos Inter.c.a.mbio sobre Centroamérica y el Caribe, 16(2). Recuperado de https://doi.org/10.15517/c.a.v16i2.37746

Agudelo, Carlos. (2 de octubre de 2019b). The Garífuna community of Triunfo de la Cruz versus the State of Honduras: territory and the possibilities and limits of the Inter-American Court of human rights verdict. Latin American and Caribbean Ethnic Studies, 14(3), 318-333. Recuperado de https://doi. org/10.1080/17442222.2019.1673069

Alves, Jaime A. (2018). The Anti-Black City: Police Terror and Black Urban Life in Brazil. Minneapolis: The University of Minnesota Press.

Articulación Regional de Afrodescendientes de las Américas y El Caribe [ARAAC]. (9 de noviembre de 2020). Crisis civilizatoria, pandemia y racismo. Manifiesto. Recuperado de https://issuu.com/araac.afrodescendientes/ docs/manifiesto_araac_crisis_civilizatoria_pandemia_y_r

Awasqa. The Green Network Project. (6 de abril de 2020). Honduras: El pueblo Garífuna busca soluciones comunitarias a la pandemia. Recuperado de https://greennetworkproject.org/es/2020/04/06/ honduras-el-pueblo-garifuna-busca-soluciones-comunitarias/

Badie, Bertrand. (2 de abril de 2020). La acción de la OMS se reduce a leer cada noche un comunicado. ICBC Fundation. Recuperado de https:// www.biblioteca.fundacionicbc.edu.ar/index.php/Bertrand_Badie, polit \% C3\%B3logo:_\%E2\% 80\% 9CLa_acci\%C3\%B3n_de_la_OMS_se_ reduce_a_leer_cada_noche_un_comunicado $\% 22$ 
Banco Interamericano de Desarrollo [BID] y Banco Mundial [BM]. (29 de agosto de 2018). Afrodescendientes en Latinoamérica. Hacia un marco de inclusión. Recuperado de https://www.bancomundial.org/es/ events/2018/08/10/afrodescendientes-en-latinoamerica

Banco Mundial. (8 de junio de 2020a) Projected poverty impacts of COVID-19 (coronavirus). Recuperado de http://pubdocs.worldbank.org/ en/461601591649316722/Projected-poverty-impacts-of-COVID-19.pdf

Banco Mundial. (8 de junio de 2020b). La COVID-19 (coronavirus) hunde a la economía mundial en la peor recesión desde la Segunda Guerra Mundial. Recuperado de https://www.bancomundial.org/es/news/press-release/2020/06/08/COVID-19-to-plunge-global-economy-into-worst-recessionsince-world-war-ii

Castels, Manuel. (2020). Reset. En Breno Bringel y Geoffrey Pleyers (Eds.), Alerta global. Políticas, movimientos sociales y futuros en disputa en tiempos de pandemia (pp. 101-106). Buenos Aires: Consejo Latinoamericano de Ciencias Sociales. Recuperado de http://biblioteca.clacso.edu.ar/clacso/ se/20200826014541/Alerta-global.pdf

Briones, Claudia; Lanata, José Luis y Monjeau, Adrián. (2019). El futuro del Antropoceno. Utopía y Praxis Latinoamericana, 24(84). Recuperado de http://www.redalyc.org/articulo.oa?id = 27961130001

Campoalegre, Rosa. (2017). Más allá del decenio internacional de los pueblos afrodescendientes: Afroepistemologías. En Rosa Campoalegre Septien y Karina Bidaseca (Eds.), Más allá del decenio internacional de los pueblos afrodescendientes (pp. 27-41). Buenos Aires: Consejo Latinoamericano de Ciencias Sociales.

Centro de Estudio para la Democracia [CESPAD]. (s.f.). La respuesta del pueblo garífuna al COVID19, en Honduras. Recuperado de http://cespad.org.hn/ garifunas-codiv19/

Coalición Negra por Derechos. (22 de marzo de 2020). Nota da coalização negra por direitos sobre o COVID-19. Recuperado de https://www.geledes. org.br/nota-da-coalizacao-negra-por-direitos-sobre-o-COVID-19/

Comisión Económica para América Latina y el Caribe [CEPAL]. (2018). Mujeres afrodescendientes en América Latina y el Caribe, deudas de igualdad. 
Recuperado de https://www.cepal.org/es/publicaciones/43746-mujeresafrodescendientes-america-latina-caribe-deudas-igualdad

Comisión Económica para América Latina y el Caribe. (Julio de 2018). Mujeres afrodescendientes en América Latina y el Caribe, deudas de igualdad. Recuperado de https://www.cepal.org/es/publicaciones/43746-mujeresafrodescendientes-america-latina-caribe-deudas-igualdad

Comisión Económica para América Latina y el Caribe. (28 de mayo de 2020). Informe sobre el impacto económico en América Latina y el Caribe de la enfermedad por coronavirus (COVID-19). Recuperado de https://www. cepal.org/es/publicaciones/45602-informe-impacto-economico-americalatina-caribe-la-enfermedad-coronavirus-COVID

Comisión Económica para América Latina y el Caribe. (2020). Aprender la historia, atender la emergencia, reprensar el futuro. México, Centroamérica y el Caribe frente a la pandemia: diagnóstico y perspectivas. Ciudad de México: Naciones Unidas. Recuperado de https://repositorio.cepal.org/bitstream/ handle/11362/45818/10/S2000634_es.pdf

Comisión Económica para América Latina y el Caribe [CEPAL], Fondo de Poblaciones de Naciones Unidas [UNFPA]. (2020). Afrodescendientes y la matriz de la desigualdad social en América Latina: retos para la inclusión. Recuperado de https://repositorio.cepal.org/bitstream/handle/11362/21835/4/ S20131037_es.pdf

Comisión Económica para América Latina y el Caribe, Fondo de Poblaciones de Naciones Unidas. (2020). Afrodescendientes y la matriz de la desigualdad social en América Latina: retos para la inclusión. Recuperado de https:// repositorio.cepal.org/bitstream/handle/11362/21835/4/S20131037_es.pdf

Comisión Económica para América Latina y el Caribe, Organización Panamericana de la Salud, Fondo de Población de las Naciones Unidas. (2017). Situación de las personas afrodescendientes en América Latina y desafíos de políticas para la garantía de sus derechos. (LC/TS.2017/121), Recuperado de https://www.cepal.org/es/publicaciones/42654-situacion-personasafrodescendientes-america-latina-desafios-politicas-la

Comisión Interamericana de Derechos Humanos [CIDH]. (10 de abril de 2020). Pandemia y Derechos Humanos en las Américas. Recuperado de https:// www.oas.org/es/cidh/decisiones/pdf/Resolucion-1-20-es.pdf 
Comisión Mundial sobre el Medio Ambiente y el Desarrollo. (Abril de 1987). Nuestro futuro común Recuperado de http://www.upv.es/contenidos/ CAMUNISO/info/U0506189

Consejo Latinoamericano de Ciencias Sociales [CLACSO]. (Mayo de 2020a). Ancestralidad, antirracismo y actualidades. La pandemia racializada. Debates desde la afroepistemología (I). Recuperado de https://www.clacso. org/boletin-1-ancestralidad-antirracismo-y-actualidades-la-pandemia-racializada-debates-desde-la-afroespistemologia-i/

Consejo Latinoamericano de Ciencias Sociales. (Junio de 2020b). Ancestralidad, antirracismo y actualidades. La pandemia racializada. Debates desde la afroepistemología (II). Recuperado de https://www.clacso.org/boletin2-ancestralidad-antirracismo-y-actualidades-la-pandemia-racializada-debates-desde-la-afroepistemologia-ii/

Consejo Latinoamericano de Ciencias Sociales. (Julio de 2020c). Ancestralidad, antirracismo y actualidades. La pandemia racializada. Debates desde la afroepistemología (III). Recuperado de https://www.clacso.org/boletin1-ancestralidad-antirracismo-y-actualidades-la-pandemia-racializada-debates-desde-la-afroespistemologia-iii/

Consejo Latinoamericano de Ciencias Sociales. (Junio de 2020d). Nuestra Afroamérica: Crisis, afrodescendientes, movimientos. Polifonía por la vida: de la coronacrisis a la primavera de ébano. Recuperado de https://www.clacso. org/boletin-1-nuestra-afroamerica-crisis-afrodescendientes-movimientos/

Consejo Nacional de Paz Afrocolombiana [CONPA]. (30 de marzo de 2020). Directrices para responder al COVID-19 para el pueblo y comunidades afrodescendientes en Colombia. Recuperado de https://renacientes.net/ blog/2020/03/30/directrices-para-responder-al-COVID-19-para-el-puebloy-comunidades-afrodescendientes-en-colombia/

Coordenaçâo Nacional de Articulçâo das Comunidades Negras Rurais Quilombolas [CONAQ]. (2018). Racismo e violencia contra Quilombos no Brasil. Recuperado de https://terradedireitos.org.br/uploads/arquivos/(final)Racismo-e-Violencia-Quilombola_CONAQ_Terra-de-Direitos_FN_WEB.pdf

Coordinación Nacional de Entidades Negras [CONEN]. (Abril de 2020). Salvar vidas y garantizar derechos de la población negra. Recuperado de https:// www.cacso.org/wp-content/uploads/2020/05/cartilha-corona-conenESPANOL.pdf 
Da Silva, Joselina y Euclides, María. (2020). A casa grande e o COVID-19. A trabalhadora doméstica no pais da democracia racial. Ancestralidad, antirracismo y actualidades, 47-58. Recuperado de https://www.clacso.org/ boletin-1-ancestralidad-antirracismo-y-actualidades-la-pandemia-racializada-debates-desde-la-afroespistemologia-iii/

Duarte, Carlos; Andrade, Óscar; Castaño, Alen; Díaz, Lina; Lacoste, Bárbara... Recalde, Stephanía. (2020). Pacífico en conflicto: dinámicas históricas y territoriales de la guerra 1958-2016. Cali: Grupo de Editoriales Universitarias del Pacífico.

Duarte, Carlos; Diaz, Lina y Salgado, Carlos. (6 de mayo de 2020): Pacífico colombiano y COVID-19: curvas epidemiológicas SIR. Recuperado de https://lasillavacia.com/silla-llena/red-etnica/pacifico-colombiano-yCOVID-19-curvas-epidemiologicas-sir-76222

Fondo de Población de Naciones Unidas. (28 de abril de 2020). Implicaciones del COVID-19 en la población afrodescendiente de América Latina y el Caribe. Recuperado de https://lac.unfpa.org/sites/default/files/pub-pdf/2COVID-Afrodescendientes $\% 20 \% 281 \% 29$.pdf

Global Human Rights Clinic. (s.f.). Protecting human rights, advancing global justice. Recuperado de https://www.law.uchicago.edu/ghrc

Grupo de Trabajo de Expertos de las Naciones Unidas sobre Afrodescendientes. (6 de abril de 2020). Statement on COVID-19: Racial equity and racial equality must guide State action. Recuperado de https://www.ohchr.org/EN/ NewsEvents/Pages/DisplayNews.aspx?LangID = E\&NewsID = 25768

Grupo Intergubernamental de Expertos sobre el Cambio Climático [IPCC]. (2014). Cambio climático 2014. Informe de síntesis. Recuperado de https:// www.ipcc.ch/site/assets/uploads/2018/02/SYR_AR5_FINAL_full_es.pdf

Guterres, Antonio. (23de septiembre de 2020). A 10 años del acuerdo mundial para proteger la biodiversidad, las tasas de extinction son las más altas de la historia. Noticias ONU. Recuperado de https://news.un.org/es/ story/2020/09/1481372

Hooker, Juliet (Ed). (2020). Black and Indigenous Resistance in the Americas: From Multiculturalism to Racist Backlash. London: Lexington Books. 
Institut de Recherche pour le Développement [IRD]. (s.f.). Proyecto Afrodescendientes y esclavitudes: dominación, identificación y herencias en las Américas.

Instituto Brasileño de Geografía y Estadística [IBGE]. (2010). Censo demográfico. Recuperado de https://www.ibge.gov.br/estatisticas/sociais/ populacao/9662-censo-demografico-2010.html?edicao $=9673 \& t=$

Lander, Edgardo. (2015). Crisis civilizatoria, límites del planeta, asaltos a la democracia y pueblos en resistencia. Estudios Latinoamericanos, (36), 29-58.

Lander, Edgardo. (2019). Crisis civilizatoria. Experiencias de los gobiernos progresistas y debates en la izquierda latinoamericana. Bielefeld: Center for Advanced Latin American Studies. Recuperado de https://doi. org/10.14361/9783839448892

Latour, Bruno. (2015). Face à Gaïa: Huit conférences sur le nouveau régime climatique. Paris: La Découverte.

Latour, Bruno. (2017). Cara a cara con el planeta. Una nueva mirada sobre el cambio climático alejada de las posiciones apocalípticas. Buenos Aires: Siglo XXI Editores.

Loperena, Christopher. (2017). Settler violence?: Race and Emergent Frontiers of Progress in Honduras. American Quarterly, 69(4), 801-807.

Mauss, Marcel. (1973). Essai sur le don. Forme et raison de l'échange dans les sociétés archaïques. Paris: Presses Universitaires de France.

Ministerio de Salud. (25 de marzo de 2020). Lineamientos para la prevención, detección y manejo de casos de coronavirus (COVID-19) para población étnica en Colombia. Recuperado de https://www.minsalud.gov.co/RID/ asif13-poblacion-etnica-COVID-19-t.pdf

Ministerio de Salud Pública. (13 de abril de 2020). Recomendaciones para la prevención del COVID-19 en población afrodescendiente. Recuperado de https://COVID19-evidence.paho.org/handle/20.500.12663/1853?show =f ull

Miranda, Miriam. (Abril, 2020). Mensaje sobre la pandemia de la COVID-19 y la respuesta de comunidades garífunas [audio]. Recuperado de https:// soundcloud.com/ofraneh-garifuna 
Moore, Jason. (2017). The Capitalocene Part I: On the nature and origins of our ecological crisis. The Journal of Peasant Studies, 44(3), 594-630.

Morrison, Judith. (24 de abril de 2020). Ser afrodescendiente durante el COVID-19: exposición y desigualdades. Recuperado de https://blogs.iadb.org/ igualdad/es/ser-afrodescendiente-durante-el-COVID-19/

Nações Unidas Brasil. (21 de janeiro de 2021). "Estamos trabalhando por sobrevivência”, conta coordenadora do escritório do Fundo de População da ONU em Manaus. Recuperado de https://nacoesunidas.org/docs/etnico-raciais

Nota da coalização negra por direitos sobre o COVID-19. (22 de marzo de 2020). Recuperado de https://www.geledes.org.br/nota-dacoalizacao-negra-por-direitos-sobre-o-COVID-19/

Organización de Desarrollo Comunitario. (s.f.). Odeco continúa en Acción apoyando a las Comunidades Afrohondureñas en tiempos de COVID-19. Recuperado de http://odecohn.blogspot.com/2020/07/odeco-continua-enaccion-apoyando-las.html

Organización de Estados Americanos [OEA]. (2020). Guía práctica de respuestas inclusivas y con enfoque de derechos ante el COVID-19 en las Américas. Recuperado de http://www.oas.org/es/sadye/publicaciones/GUIA_SPA.pdf

Organización de las Naciones Unidas [ONU]. (7 de febrero de 2014). Programa de Actividades del Decenio Internacional para los Afrodescendientes 2015-2024. Recuperado de https://www.un.org/es/observances/ decade-people-african-descent/programme-activities

Organización de las Naciones Unidas. (25 de septiembre de 2015). La Asamblea General adopta la Agenda 2030 para el Desarrollo Sostenible. Recuperado de https://www.un.org/sustainabledevelopment/es/2015/09/ la-asamblea-general-adopta-la-agenda-2030-para-el-desarrollo-sostenible/

Organización de las Naciones Unidas. (2020a). World Social Report 2020. Inequality in a Rapidly Changing World. Recuperado de https://www. un.org/development/desa/dspd/wp-content/uploads/sites/22/2020/02/ World-Social-Report2020-FullReport.pdf

Organización de las Naciones Unidas. (6 de abril de 2020b). Racial equity and equality must guide state action in COVID-19 response, say UN experts. 
Recuperado de https://www.ohchr.org/EN/NewsEvents/Pages/DisplayNews.aspx? NewsID $=25776 \&$ LangID $=\mathrm{E}$

Organización de Naciones Unidas, Oficina del Alto Comisionado de las Naciones Unidas para los Derechos Humanos. (2014). Decenio Internacional de los Afrodescendientes (2015-2024).

Organización Fraternal Negra Hondureña [OFRANEH]. (30 de marzo de 2020a). Organizadas y con prácticas ancestrales comunidades garífunas hacen frente al COVID-19. Recuperado de https://radioprogresohn.net/portada/organizadas-y-con-practicas-ancestrales-garifunas-hacen-frente-al-COVID-19/

Organización Fraternal Negra Hondureña. (Abri, 2020b). Miriam Miranda, OFRANEH, sobre la pandemia COVID19 y la respuesta de comunidades Garifunas. Recuperado de https://soundcloud.com/ofraneh-garifuna

Organización Panamericana de la Salud [OPS]. (28 de septiembre de 2017). Política sobre etnicidad y salud. Recuperado de https://www.paho.org/es/ file $/ 51612 /$ download?token $=$ jbssGutj

Organización Panamericana de la Salud. (12 de octubre de 2019). Estrategia y plan de acción sobre etnicidad y salud 2019-2025. Recuperado de https:// iris.paho.org/handle/10665.2/51745

Organización Panamericana de la Salud. (4 de junio de 2020). Consideraciones relativas a los pueblos indígenas, afrodescendientes y otros grupos étnicos durante la pandemia de COVID-19. Recuperado de https://www.paho.org/ es/documentos/consideraciones-relativas-pueblos-indigenas-afrodescendientes-otros-grupos-etnicos

Oxford Committee for Famine Relief [OXFAM]. (2015). Privilegios que niegan derechos. Desigualdad extrema y secuestro de la democracia en América Latina y el Caribe. https://www-cdn.oxfam.org/s3fs-public/file_attachments/reporte_iguales-oxfambr.pdf

Oxford Committee for Famine Relief. (2018). Informe sobre desigualdad global 2018. Recuperado de https://wir2018.wid.world/files/download/wir2018summary-spanish.pdf

Pacto Ecosocial del Sur. (2020). Por un pacto social, ecológico, económico e intercultural para América Latina. https://www.clacso.org/por-un-pactosocial-ecologico-economico-e-intercultural-para-america-latina/ 
Proceso de Comunidades Negras [PCN]. (15 de septiembre de 2020). Informe: situación del pueblo negro, afrodescendiente, raizal y palenquero en Colombia en el marco del COVID-19 aprendizajes y desafios. Recuperado de https://renacientes.net/blog/2020/09/15/situacion-de-los-pueblos-narpen-colombia-en-el-marco-del-COVID-19-aprendizajes-y-desafios/

Programa de Naciones Unidas para el Desarrollo [PNUD]. (2010a). Derechos de la población afrodescendiente de América Latina: Desafíos para su implementación. Recuperado de https://es.slideshare.net/AshantiPeru/ derechos-de-la-poblacion-afrodescendiente-en-america-latina-31055545

Programa de Naciones Unidas para el Desarrollo. (2010b). Proyecto Regional Población afrodescendiente de América Latina.

Programa de Naciones Unidas para el Desarrollo. (2019). Human Development Report 2019 Beyond income, beyond averages, beyond today: Inequalities in human development in the 21st century. Recuperado de http://hdr.undp. org/sites/default/files/hdr2019.pdf

Programa de Naciones Unidas para el Desarrollo. (21 de mayo de 2020). COVID-19 y la protección social de las personas pobres y los grupos vulnerables en América Latina: un marco conceptual. Recuperado de https://www. latinamerica.undp.org/content/rblac/es/home/library/crisis_prevention_ and_recovery/COVID-19-and-social-protection-of-poor-and-vulnerablegroups-in-.html

Ramonet, Ignacio. (28 de abril de 2020). Ante lo desconocido... La pandemia y el sistema-mundo. Le Monde diplomatique. Recuperado de https://www. aesed.com/es/la-pandemia-y-el-sistema-mundo

Svampa, Maristella. (13 de agosto de 2016). El Antropoceno, un concepto que sintetiza la crisis civilizatoria. La Izquierda Diario. Recuperado de http://www.laizquierdadiario.com/ El-Antropoceno-un-concepto-que-sintetiza-la-crisis-civilizatoria

Telles, Edward and Project on Ethnicity and Race in Latin America. (2014). Pigmentocracies. Ethnicity, Race, and Color in Latin America. Chapel Hill: University of North Carolina Press.

United Nations. Human Rights. Office of the High Commissioner. (April 6, 2020). Racial equity and equality must guide state action in COVID-19 
response, say UN experts. Recuperado de https://www.ohchr.org/EN/NewsEvents/Pages/DisplayNews.aspx?NewsID $=25776 \&$ LangID $=\mathrm{E}$

Valenti, Manuel. (2020). Pensar la pandemia. Observatorio social del coronavirus. La pandemia de las desigualdades. Recuperado de https://www. clacso.org/la-pandemia-de-las-desigualdades /

Viveros, Mara. (19 de octubre de 2016). La interseccionalidad: una aproximación situada a la dominación. Debate Feminista, 52, 1-17. Recuperado de http://dx.doi.org/10.1016/j.df.2016.09.005

Wallace, Arturo. (3 de junio de 2020). Muerte de George Floyd: el país latinoamericano donde la policía mata a más negros que en Estados Unidos. Recuperado de https://www.bbc.com/mundo/noticias-america-latina-52911312

Wellenstein, Anna; González, María y Freire, Germán. (7 de julio de 2020). Afrolatinos, raza e inclusión social en tiempos de COVID-19. Recuperado de https://blogs.worldbank.org/es/latinamerica/ afrolatinos-raza-e-inclusion-social-en-tiempos-de-COVID-19

Werner, Alejandro. (s.f.). Política económica en América Latina y el Caribe en tiempo de la COVID-19. (blog). Diálogo a fondo. Recuperado de https:// blog-dialogoafondo.imf.org/?p = 13241

World Inequality Lab. (2018). Informe sobre la desigualdad global. Resumen ejecutivo. Paris: Autor. Recuperado de https://wir2018.wid.world/files/ download/wir2018-summary-spanish.pdf

Žižek, Slavoj. (2020). El coronavirus es un golpe al capitalismo a lo Kill Bill. En Pablo Amadeo (Ed.), Sopa de Wuhan (pp. 21-28). Buenos Aires: ASPO. 